\title{
Molecular basis of degenerative spinal disorders from a proteomic perspective (Review)
}

\author{
CHANG LIU $^{1}$, MINGHUI YANG ${ }^{1}$, LIBANGXI LIU ${ }^{1}$, YANG ZHANG ${ }^{1}$, \\ QI ZHU ${ }^{2}$, CONG HUANG $^{1}$, HONGWEI WANG $^{3}$, YAQING ZHANG ${ }^{1}$, HAIYIN LI $^{1}$, \\ CHANGQING $\mathrm{LI}^{1}$, BO HUANG ${ }^{1}$, CHENCHENG FENG ${ }^{1}$ and YUE ZHOU ${ }^{1}$ \\ ${ }^{1}$ Department of Orthopedics, Xinqiao Hospital, Army Medical University; ${ }^{2}$ Medical Research Center, \\ Southwestern Hospital, Army Medical University, Chongqing 400037; ${ }^{3}$ Department of Orthopedics, General Hospital of \\ Shenyang Military Area Command of Chinese PLA, Shenyang, Liaoning 110016, P.R. China
}

Received March 20, 2019; Accepted October 16, 2019

DOI: $10.3892 / \mathrm{mmr} .2019 .10812$

\begin{abstract}
Intervertebral disc degeneration (IDD) and ligamentum flavum hypertrophy (LFH) are major causes of degenerative spinal disorders. Comparative and proteomic analysis was used to identify differentially expressed proteins (DEPs) in IDD and LFH discs compared with normal discs.

Correspondence to: Professor Yue Zhou or Dr Chencheng Feng, Department of Orthopedics, Xinqiao Hospital, Army Medical University, 183 Xinqiao Main Street, Shapingba, Chongqing 400037, P.R. China

E-mail: happyzhou@vip.163.com

E-mail: doctorfgy@163.com
\end{abstract}

Abbreviations: ADORA3, adenosine receptor A3; AF, annulus fibrosus; AGE-RAGE, advanced glycation endproducts-receptor for advanced glycation endproducts; APO, apolipoprotein; CHAD, chondroadherin; COL1, type I collagen; COL2, type II collagen; COL3, type III collagen; COL2A1, $\alpha-1$ type II collagen; COMP, cartilage oligomeric matrix protein; CSF, cerebrospinal fluid; DEP, differentially expressed protein; FAR1, fatty acyl-CoA reductase 1; FN1, fibronectin 1; G6PD, glucose-6-phosphate 1-dehydrogenase; GAG, glycosaminoglycan; GNAI2, guanine nucleotide-binding protein G(i) subunit $\alpha-2$; HSPA8, heat shock cognate $71-\mathrm{kDa}$ protein; HTRA1, serine protease HTRA1; IDD, intervertebral disc degeneration; IVD, intervertebral disc; KCND3, potassium voltage-gated channel subfamily D member 3; KEGG, Kyoto Encyclopedia of Genes and Genomes; LBP, lower back pain; LDH, lumbar disk herniation; LF, ligamentum flavum; LFH, ligamentum flavum hypertrophy; LPA, lysophosphatidic acid; LPPR2, lipid phosphate phosphatase-related protein 2; LSS, lumbar spinal stenosis; MSC, mesenchymal stem cell; NC, notochordal cell; NP, nucleus pulposus; OA, osteoarthritis; PG, proteoglycan; SLRP, small leucine-rich proteoglycan; SOD, superoxide dismutase; SOX9, SRY-related protein 9; TGF- $\beta$, transforming growth factor- $\beta$; TMEM51, transmembrane protein 51 ; TNF- $\alpha$, tumor necrosis factor- $\alpha$; UBAC1, ubiquitin-associated domain-containing protein 1

Key words: degenerative spinal disorders, intervertebral disc degeneration, ligamentum flavum hypertrophy, gene ontology term enrichment analysis, Kyoto Encyclopedia of Genes and Genomes pathway enrichment analysis
Subsequent gene ontology term enrichment analysis and Kyoto Encyclopedia of Genes and Genomes pathway enrichment analysis of the DEPs in human IDD discs or LFH samples were performed to identify the biological processes and signaling pathways involved in IDD and LFH. The PI3K-AKT signaling pathway, advanced glycation endproducts-receptor for advanced glycation endproducts signaling pathway, p53 signaling pathway, and transforming growth factor-b signaling pathway were activated in disc degeneration. This review summarizes the recently identified DEPs, including prolargin, fibronectin 1, cartilage intermediate layer protein, cartilage oligomeric matrix protein, and collagen types I, II and IV, and their pathophysiological roles in degenerative spinal disorders, and may provide a deeper understanding of the pathological processes of human generative spinal disorders. The present review aimed to summarize significantly changed proteins in degenerative spinal disorders and provide a deeper understanding to prevent these diseases.

\section{Contents}

1. Introduction

2. Kyoto Encyclopedia of Genes and Genomes (KEGG) analysis

3. Proteomic analysis of the human LF

4. Proteomic analysis of the human AF

5. Proteomic analysis of the human NP

6. Comparative proteomic analysis of IDD model mice

7. Clinical proteomic analysis of body fluids from patients with degenerative spinal disorders

8. Differentially regulated proteins and their signaling pathways in degenerative spinal disorders

9. Conclusions

\section{Introduction}

Lower back pain (LBP) and other clinical symptoms occur as a result of degenerative spinal disorders, which includes disc degeneration, facet joint degeneration, and adjacent segment disease (1). Intervertebral disc degeneration (IDD) 
and ligamentum flavum hypertrophy (LFH) are most common degenerative spinal disorders $(2,3)$. Intervertebral discs (IVDs) are elastic joint tissues between vertebral bodies that bear the load of daily activities and are more susceptible to degeneration because of the upright posture of humans (4). IDD is a major cause of LBP and sciatica, with the severity of LBP depending on the pathological grading of IDD because the pathology depresses the normal function of IVDs $(5,6)$. LFH and IDD are exacerbated by increased cellular apoptosis and senescence, and the upregulation of pro-inflammatory cytokines and proteins, which results from the turnover of the matrix in IVDs and the ligamentum flavum (LF) $(7,8)$. Furthermore, aging (especially over the age of 50) (2) and several environmental factors (such as oxygen, mechanical stress and osmotic pressure) have been reported to trigger the onset and progression of IDD (9). Nevertheless, the pathophysiological mechanisms of IDD and LFH remain poorly understood.

A number of high-throughput proteomic analysis techniques, such as isobaric tags for relative and absolute quantification (iTRAQ), have been used to profile the proteomic map of the annulus fibrosus (AF) and nucleus pulposus (NP; Table I). NP is a gel-like tissue which is surrounded by AF, a layered cartilaginous structure. The present review summarizes the results of quantitative proteomic studies of the LF, $\mathrm{AF}$, and NP, as well as body fluids, including cerebrospinal fluid (CSF) and serum from patients with degenerative spinal disorders. The aim of this review was to identify the crucial proteins mediating the onset and progression of IDD and LFH, which may facilitate the development of novel potential therapies for these disorders.

\section{Kyoto Encyclopedia of Genes and Genomes (KEGG) analysis}

Methods. To conduct KEGG pathway analysis, 54 differentially expressed proteins (DEPs) from LF tissue, 15 DEPs from the AF (soluble, the supernatant of samples), 10 DEPs from AF (insoluble, the lyophilized pellet of samples), 21 DEPs from NP (soluble), and 7 DEPs from NP (insoluble) were selected based on previous proteomic studies (Table SI) $(10,11)$; patient information is provided in Table SII. Briefly, for the LF, the DEPs were selected according to the protein expression ratio between lumbar spinal stenosis (LSS) and the control (individuals with disc herniation; protein expression ratio=LSS/control, $\geq 2$ or $\leq 0.5)$ (11). For the AF and NP, genes which encoded DEPs that were significantly increased or decreased in the degenerative samples compared with control samples were selected $(\mathrm{P}<0.05)(10)$.

The KEGG pathway analysis database (http://www.genome. $\mathrm{jp} / \mathrm{kegg}$ ) was used to identify signaling pathways enriched by genes which encoded DEPs and the KEGG Orthology-Based Annotation System (KOBAS) version 3.0 (http://kobas.cbi. pku.edu.cn) was used to investigate gene/protein functional annotation and gene set enrichment (12-14). The module of KOBAS called 'Gene List Enrichment', based on the first gene set enrichment method, overrepresentation analysis, was used for KEGG pathway analysis. Statistical analysis was performed using a hypergeometric test and Fisher's exact test. $\mathrm{P}<0.05$ was considered to indicate a statistically significant difference.
Results. KEGG pathway analysis indicated that multiple pathways were involved in LFH and the degeneration of AF and NP. Some were the same in LF, AF and NP, such as ECM-receptor interaction and focal adhesion. The total enrichment pathways are presented in Table SIII. The top 10 KEGG pathways enriched with DEPs, including protein digestion and absorption, ECM-receptor interaction and focal adhesion, are presented in Figs. 1B and 2. The p53 signaling pathway, advanced glycation endproduct-receptor for advanced glycation endproducts signaling pathway (AGE-RAGE), PI3K/AKT signaling pathway, and transforming growth factor (TGF)- $\beta$ signaling pathway were enriched by these DEPs (Table II). These four signaling pathways were not in the top 10 pathways in LF, but they were still enriched by DEPs (Table SIII). This review combines past proteomic analyses with present analysis to provide a deeper understanding of the molecular mechanisms of degenerative diseases of the spine.

\section{Proteomic analysis of the human LF}

Structural proteomic analysis of the LF. Hypertrophy and ossification of the LF are major causes of $\operatorname{LSS}(15,16)$. However, the proteins involved in hypertrophy of the LF remain unknown. To clarify the molecular events during LSS disease progression and to identify targets for treatment, LF proteomic analysis was employed using 2-dimensional image converted analysis of liquid chromatography (2DICAL)-based label-free proteomics. A set of small leucine-rich proteoglycans (SLRPs), including asporin, decorin, and fibromodulin were identified, in addition to the large proteoglycans (PGs), versican and aggrecan (11). These protein components suggest that the LF structure shares common features with other elastic tissues and that within normal physiology the LF is more elastic compared to other ligaments and tendons (17). This is demonstrated through the increased presence of fibulins (FBLN 1/2/3/5), elastin, and microfibril-associated protein 4 (10). Redox proteins present in the LF, including lysyl oxidase homolog 1 and superoxide dismutase (SOD) 3, are considered to be involved in the formation and regulation of these elastic fibers $(18,19)$. The proteins identified in the human LF were classified into 24 cellular components by gene ontology (GO) term enrichment analysis (Fig. 1A) (11).

Comparative proteomic analysis of the LF. A number of proteins were identified through Selective Reaction Monitoring/Multi Reaction Monitoring in LFH samples (20) (Table I). Notably, vasculature is thought to be implicated in LFH owing to the significantly upregulated expression of plasma proteins, including fibrinogen, apolipoproteins (APOs), and transthyretin. Chondrometaplasia is also observed in degenerated LF (20); with multiple proteins involved in chondrometaplasia consistently upregulated in LFH, including chondroadherin (CHAD), prolargin, cartilage intermediate layer proteins, and aggrecan (21). These proteins have been reported to be associated with the ossification of the LF (21).

CHAD is a leucine-rich repeat (LRR) protein that is highly expressed in cartilaginous tissues (22). LRR proteins are involved in promoting interactions with other extracellular matrix (ECM) molecules and collagen fibrillogenesis (23), and are often regulated by TGF- $\beta$ (24). In addition, prolargin 

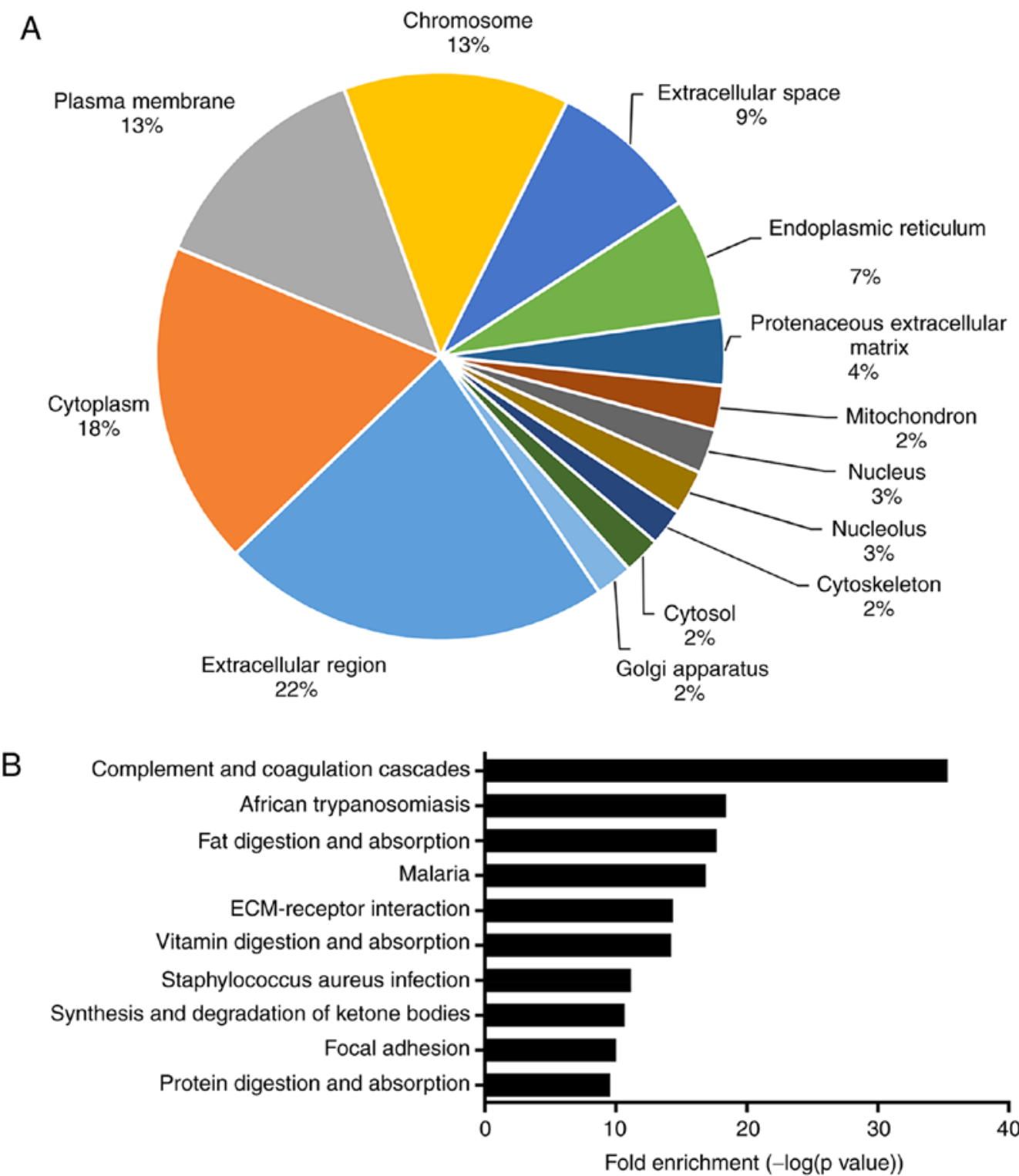

Figure 1. Proteomic characterization of the human ligamentum flavum in lumbar spinal stenosis. (A) Gene Ontology term enrichment analysis of unique proteins. (B) Top 10 Kyoto Encyclopedia of Genes and Genomes pathways enriched by differentially expressed proteins (54 proteins). ECM, extracellular matrix.

and SLRPs isolated from mice lacking decorin are reportedly involved in collagen fiber assembly and fibril abnormalities (25). Thus, the interactions between molecules in the ECM and collagen fibrillogenesis may directly influence the structure of the LF, and may be involved in the process of degeneration.

In vitro studies have demonstrated that cartilage intermediate layer protein (CILP) modulates TGF- $\beta$ signaling (26), and TGF- $\beta$ has been detected in the early stages of degenerative hypertrophy of the LF (27). Furthermore, the expression of lysophosphatidic acid (LPA), and its receptor, LPA receptor 1 (LPAR1), are significantly upregulated in samples isolated from LFH specimens (11). Previous studies from Japan and Finland have reported that LPA is closely related to the process of $\operatorname{IDD}(26,28)$, and that upon LPA interacting with LPAR1, the protein can promote LF cell proliferation and further induce LFH, through the LPAR1/AKT signaling pathway (29).

The expression levels of fibronectin 1 (FN1), tenascin, and serine protease HTRA1 (HTRA1) are positively correlated with LFH, whereas asporin expression is negatively correlated in LFH (11). The level of peptides derived from FN1 is influenced by HTRA1, and the HTRA1 mutation causes diseases such as cerebral autosomal recessive arteriopathy and leukoencephalopathy (30). In addition, HTRA1 upregulation is observed in many degenerative disorders, including age-related macular degeneration, osteoarthritis (OA), and lumbar disc degeneration (31-33), with a previous study reporting that FNS is regulated by HTRA1 in joints affected by OA (34).

\section{Proteomic analysis of the human AF}

Structural proteomic analysis of the AF. The spine resists multidirectional loading from the radial, axial, and circumferential directions, and the upright posture of humans imposes greater mechanical loading and accelerates the process of IDD (35). IDD pathological features are accompanied by NP fibrosis, AF fissuring, and protein structure disorganization (36). Type II 
collagen (COL2), chondroitin sulfate, and PGs are produced by AF cells (37), and in healthy IVDs, the AF contains 65-70\% water; with the dry weight composed of $20 \%$ PGs, $~ 60 \%$ collagen, and $2 \%$ elastin (38). Type I collagen (COL1) extracted from AF cells is also significantly upregulated compared to COL1 extracted from NP cells, but the level of chondroitin-6-sulfated PGs demonstrates the opposite pattern (39). In IDD, changes in the level of PGs can be detected. In the early stages, AF cells proliferate with increasing biosynthetic processes, whereas in degenerated IVDs, the level of aggrecan is decreased, and the levels of decorin, biglycan, and fibromodulin (which are small PGs) are upregulated in AF cells (40). Tenomodulin levels were also reported to be increased in degenerated AF cells (41). Other genes that are correlated with AF cells in degenerated IVDs have been identified, including the gene encoding pleiotrophin, which increases in the AF with age (42); increased vascularization in the degenerated AF tissues may also be present (43). The proteome of a normal IVD from a 35-year old patient (male) has been established (10), and the cellular components from the AF (soluble and insoluble) determined by GO term enrichment analysis are presented in Fig. 3A and B. Compared with the AF (soluble), ECM proteins are present at a higher proportion in the AF (insoluble), and nuclear proteins only exist in the AF (soluble).

Comparative proteomic analysis of the AF. A previous study has identified a total of 759 proteins in non-degenerative AF tissue (44). DEPs of importance in the degenerated AF include the ubiquitin-associated domain-containing protein 1 (UBAC1), aspartyl transfer RNA synthetase, potassium voltage-gated channel subfamily D member 3 (KCND3), structural proteins, and signaling factors such as Indian hedgehog protein (44) (Table I). UBAC1 serves a prominent role in lysosomal and proteasomal degeneration $(45,46)$, and KCND3, a voltage-activated A-type potassium ion channel, is involved in degenerative diseases such as spinocerebellar ataxia (47).

Semi-quantitative analysis of silver-stained 2D electrophoresis gels of AF cells isolated from normal and degenerated IVDs has demonstrated that the expression levels of glucose-6-phosphate 1-dehydrogenase (G6PD), heat shock cognate 71-kDa protein (HSPA8), and protocadherin-23 are decreased, whereas SOD, transmembrane protein 51 (TMEM51), guanine nucleotide-binding protein $\mathrm{G}(\mathrm{i})$ subunit $\alpha-2$ (GNAI2), 26S protease regulatory subunit 8 , adenosine A3 receptor (ADORA3), fatty acyl-CoA reductase 1 (FAR1), and lipid phosphate phosphatase-related protein type 2 (LPPR2) expression levels are increased (48).

HSPA8 is a heat shock cognate protein that represses pre-mRNA splicing and forms an essential part of the spliceosome, where it is thought to be involved in spliceosome assembly (49). Thus, the low expression of HSAP8 suggests that the reduced repression of pre-mRNA splicing is a potential regulatory mechanism in the degenerated AF. G6PD is a member of the dehydrogenase family that provides pentose phosphates and serves as a reductant in fatty acid and nucleic acid synthesis (50). A significant decrease in G6PD expression in the AF suggests an important role for oxidative stress in the process of degeneration. These findings suggest that oxidative stress may be a major contributor to the process of degeneration (51). The main function of protocadherin-23 is to provide adhesion and it is involved in morphogenesis during development (52). However, the correlation between protocadherin-23 and IDD remains to be elucidated. GNAI 2 may serve as a signal transducer or modulator in multiple types of transmembrane signaling systems, as the $\alpha$-subunit GTP activating protein, GNAI2 is a regulator for the effector interaction (53). ADORA3 is an adenosine receptor and serve a role in duplication (54). Both GNAI2 and ADORA3 are associated with G-proteins (55), thus, G-proteins of the transmembrane signaling systems may be involved in the process of AF degeneration. FAR1 reduces saturated fatty acids into fatty alcohols (56). In addition, fatty alcohols accumulated in specific cell lines defective in plasmalogen biosynthesis (56). Thus, the upregulation of FAR1 suggests that plasmalogen biosynthesis may be involved in the AF degenerative process. The function of LPPR2 is similar to that of other lipid phosphate phosphatase superfamily members, which serve roles in signal transduction and extracellular concentrations of lipid phosphate esters (57); TMEM51 is a member of the multipass membrane proteins (58). However, the roles of LPPR2 and TMEM51 in AF cells are unknown, but the data suggest that these proteins may influence the process of AF cell degeneration.

\section{Proteomic analysis of the human NP}

Structural proteomic analysis of the NP. NP cells are commonly described as 'chondrocyte-like' or 'stem cell-like' owing to their morphology and the cell markers that they synthesize; the main constituents of the NP are PGs, collagen, elastin and water $(38,59)$. The PGs absorb the water in the NP, and account for $35-65 \%$ of the dry weight (60), whereas COL2 fibrils form an incompact frame structure that holds the NP tissues together. A previous study demonstrated that NP water levels decrease with age, and a similar decrease may occur in PGs (38), which would decrease the size of the NP by $\sim 50 \%$. Although the morphology of the NP is closer to a solid form than a fluid structure due to the dehydration (61), the proteome of the NP (soluble and insoluble) is similar to the AF (Fig. 3C and D). Nevertheless, PGs are more abundant in the NP (soluble and insoluble) compared with the AF (10).

Comparative proteomic analysis of the NP. Similar to the LF, cartilage oligomeric matrix protein (COMP), prolargin, FN1, and clusterin expression were upregulated in both soluble and insoluble fractions of the NP from IDD specimens (10) (Table I). Furthermore, the expression of SLRPs, such as biglycan and decorin, and extracellular SOD, were increased in the soluble fraction (10). However, Erwin et al reported that SLRPs were intact in both chondrodystrophic canines that developed early disc degeneration and non-chondrodystrophic animals (62). As previously discussed, COL2 and CHAD are closely associated with collagen fibrillogenesis and are observed to be downregulated with age (11), thus indicating that substantial matrix remodeling is involved in NP degeneration. The majority of abnormal changes in proteins are similar to those observed in the LF, except for COL1. COL1, the major component of the insoluble fraction of the degenerative NP, was present in increased amounts (10). It has been reported that COL1 is capable of achieving cross-linking, mediated by enzymatic or non-enzymatic processes (10), which is consistent with the increasing trends in the insoluble fraction of the degenerative NP. These data suggested that COL1 may be a major contributor to reducing protein solubility in degenerative discs. 
A

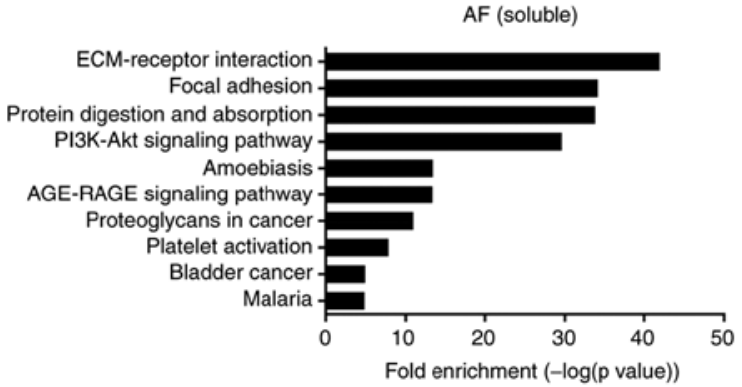

$\mathrm{C}$

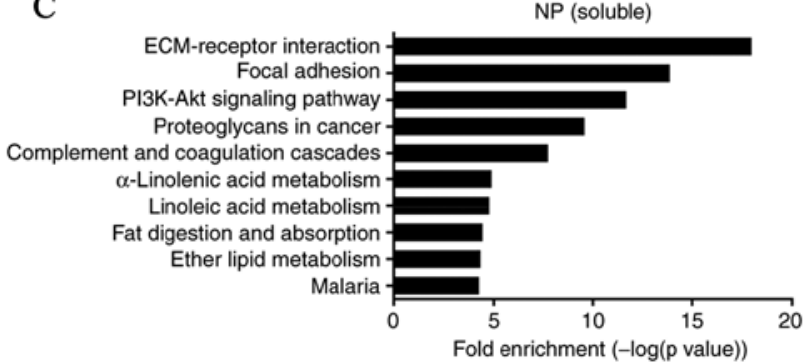

B

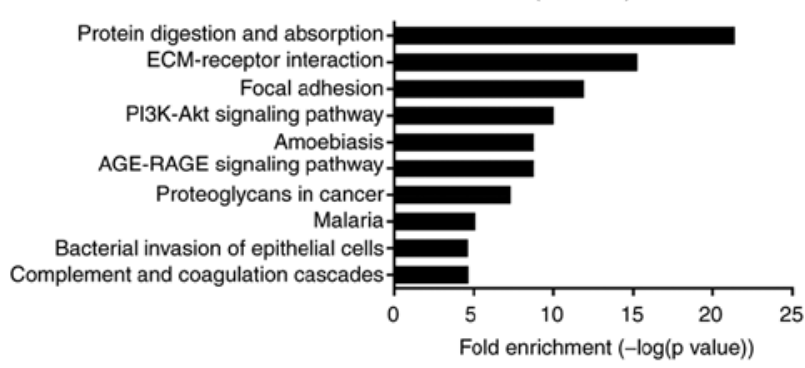

$\mathrm{D}$

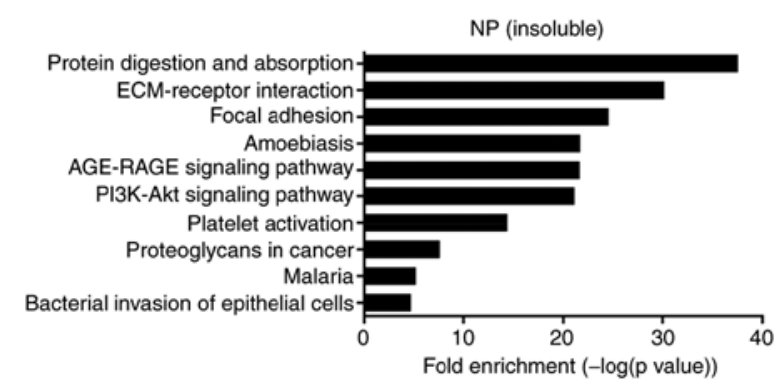

Figure 2. Top 10 KEGG pathways enriched by DEPs identified in (A) AF soluble (15 proteins), (B) AF insoluble (10 proteins), (C) NP soluble (21 proteins) and (D) NP insoluble (7 proteins) fractions. ECM, extracellular matrix; AGE-RAGE, advanced glycation endproducts-receptor for advanced glycation endproducts, AF, annulus fibrosus; NP, nucleus pulposus.
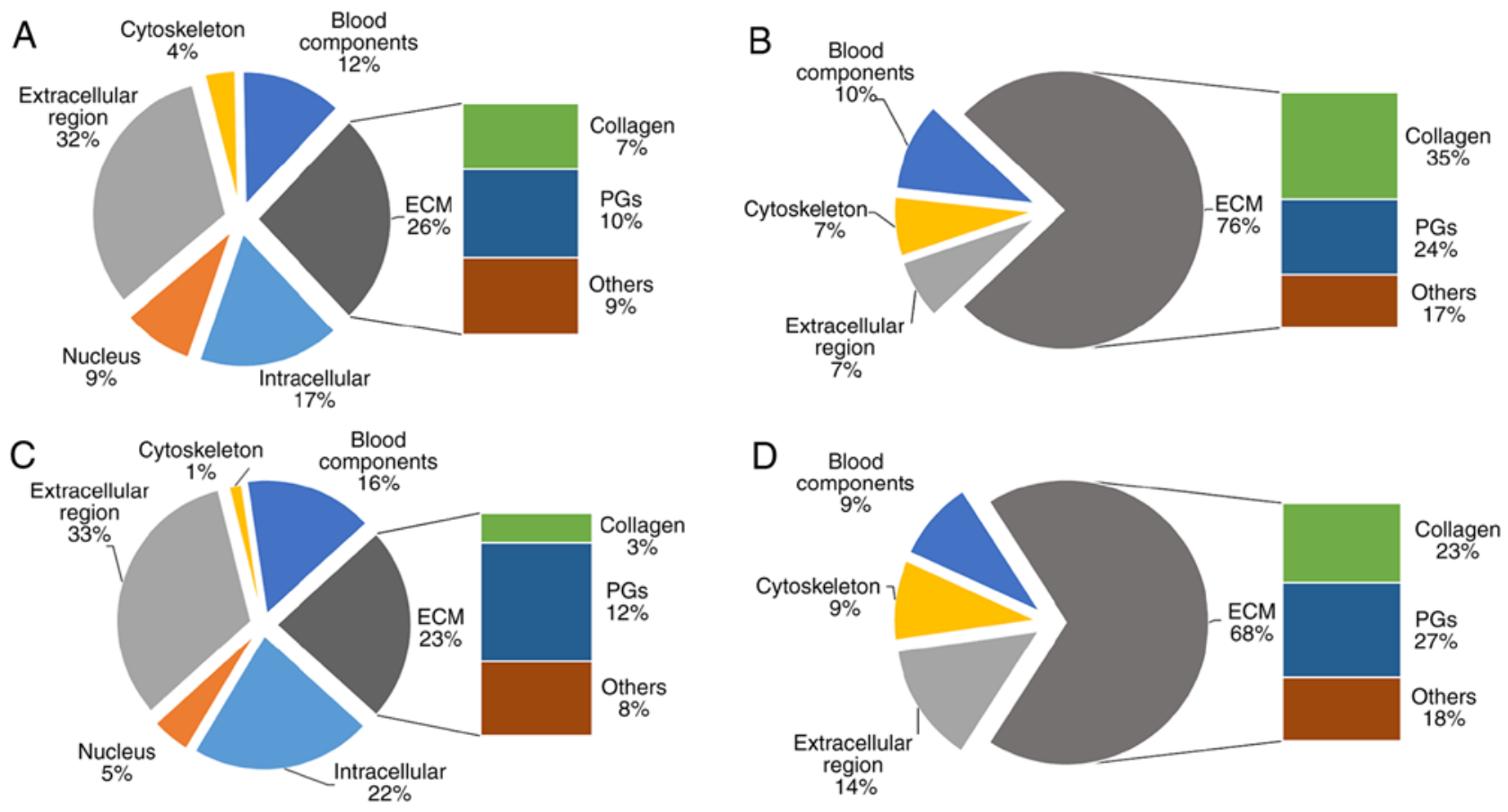

Figure 3. Structural proteomic analysis of a normal intervertebral disc from a 35-year old sample determined by GO analysis. (A-D) GO term enrichment analysis of the (A) 71 unique cellular proteins detected in the AF (soluble), (B) 24 unique proteins detected in the AF (insoluble), (C) 64 unique proteins detected in the NP (soluble), and (D) 18 unique proteins detected in the NP (insoluble). GO, gene ontology; AF, annulus fibrosus; NP, nucleus pulposus, PGs, proteoglycans; ECM, extracellular matrix.

The function of local or migratory cells in IVD is not completely understood. Nevertheless, self-repair induced by local or migratory cells has been observed in dogs with IDD induced by enzymatic digestion (63). A number of studies have transplanted bone marrow-derived mesenchymal stromal cells (BM-MSCs) and stem-like or progenitor-like cells in IDD models $(64,65)$. The transplantation of these cells activates a set of native, uncharacterized cells, which express both $\alpha-1$ COL2 (COL2A1) and SRY-related protein 9 (SOX9) (66), which postponed the onset of IDD in humans and sheep $(64,65)$. However, this evidence is not sufficiently robust to support cellular transplantation as a clinical therapy. In fact, another study reported that there was no clinically significant difference between MSC and sham treatment for IDD, regardless 
Table I. Significantly differentially expressed proteins in degenerative disc disease.

\begin{tabular}{|c|c|c|c|c|}
\hline Author, year & Sample source & Increased protein expression & $\begin{array}{l}\text { Decreased protein } \\
\text { expression }\end{array}$ & (Refs.) \\
\hline Kamita et al, 2015 & Ligamentum flavum & $\begin{array}{l}\text { Chondroadherin, cartilage } \\
\text { intermediate layer protein, } \\
\text { lysophosphatidic acid } \\
\text { receptor 1, SLRPs, prolargin, } \\
\text { FN1, HTRA serine peptidase } 1 \text {, } \\
\text { tenascin }\end{array}$ & Asporin & (11) \\
\hline Johnson et al, 2006 & Annulus fibrosus & $\begin{array}{l}\text { Ubiquitin-associated } \\
\text { domain-containing protein } 1, \\
\text { potassium voltage-gated } \\
\text { channel subfamily D member } 3\end{array}$ & NA & (39) \\
\hline Battié et al, 2008 & & $\begin{array}{l}\text { FN1, clusterin, aggrecan, } \\
\text { decorin, prolargin, }\end{array}$ & $\begin{array}{l}\text { COL2, type XI collagen, } \\
\text { COL1, COL6 }\end{array}$ & (9) \\
\hline Yee et al, 2016 & & $\begin{array}{l}\text { Guanine nucleotide-binding } \\
\text { protein } \mathrm{G}(\mathrm{i}) \text { subunit } \alpha-2, \\
\text { transmembrane protein } 51, \\
\text { adenosine receptor } \mathrm{A} 3, \mathrm{FAR} 1, \\
\text { lipid phosphate phosphatase-related } \\
\text { protein type } 2\end{array}$ & $\begin{array}{l}\text { Heat shock cognate } \\
71-\mathrm{kDA} \text { protein, } \\
\text { glucose-6-phosphate } \\
\text { dehydrogenase, } \\
\text { protocadherin- } 23\end{array}$ & $(10)$ \\
\hline Battié et al, 2008 & Nucleus pulposus & $\begin{array}{l}\text { Prolargin, FN1, COMP, clusterin, } \\
\text { SLRPs }\end{array}$ & COL1 & (9) \\
\hline Honsho et al, 2010 & $\begin{array}{l}\text { Notochordal cell } \\
\text { conditioned medium }\end{array}$ & $\begin{array}{l}\text { Laminin B1, glycosaminoglycan, } \\
\text { SOX } 9 \text {, COL2, transforming growth } \\
\text { factor } \beta 3\end{array}$ & Type III collagen & $(56)$ \\
\hline $\begin{array}{l}\text { Elliott and Setton, } \\
2001\end{array}$ & $\begin{array}{l}\text { Murine intervertebral } \\
\text { discs }\end{array}$ & $\begin{array}{l}\text { FN1, prolargin, COMP, COL6, type } \\
\text { XII collagen, type XV collagen, } \\
\text { SOX9, COL2 }\end{array}$ & NA & $(61)$ \\
\hline $\begin{array}{l}\text { Markolf and Morris, } \\
1974\end{array}$ & Cerebrospinal fluid & $\begin{array}{l}\text { APO A-IV, vitamin D-binding protein, } \\
\text { neurofilament triplet L protein, } \\
\text { tetranectin, hemoglobin, } \\
\text { immunoglobulin G }\end{array}$ & $\begin{array}{l}\text { ProSAAS, } \\
\text { prostaglandin D2 synthase, } \\
\text { creatine kinase B, } \\
\text { superoxide dismutase } 1, \\
\text { peroxiredoxin } 2\end{array}$ & (63) \\
\hline Yang et al, 2009 & Serum & APO L1 & $\begin{array}{l}\text { apolipoprotein } \mathrm{M} \text {, } \\
\text { tetranectin }\end{array}$ & $(66)$ \\
\hline
\end{tabular}

APO, apolipoprotein; COL1, type I collagen; COL2, type II collagen; COL6, type VI collagen; COMP, cartilage oligomeric matrix protein; FN1, fibronectin 1; NA, not applicable; SLRP, small leucine-rich proteoglycan; SOX9, SRY-related protein 9; ProSAAS, proprotein convertase subtilisin/kexin type 1 inhibitor.

of allogeneic or autologous transplantation methods (67). Therefore, the development of progenitor cell therapies and the identification of specific biomarkers will require a deeper understanding of progenitor cells.

Notochordal cells (NCs), which are potential progenitor cells, can induce the differentiation of MSCs to NP cells by synthesizing PGs and resisting the expression and hypertrophy of collagen fiber; this is noted through the increased production of glycosaminoglycans (GAG), laminin B1, and type III collagen (COL3) observed in human MSCs cultured in porcine notochordal conditioned medium (68). Furthermore, following MSC transplantation in animals, NCs in the native tissue promoted the upregulation expression of SOX9, COL2, and transforming growth factor $\beta 3$ (TGF- $\beta 3$ ), which are also detected in healthy NP (69-71). These data suggest that laminin B1, GAG, COL3, SOX9, and TGF- $\beta 3$ may serve vital roles in the transformation of MSCs into NP cells (72).

\section{Comparative proteomic analysis of IDD model mice}

Previous studies have established SM/J and LG/J mouse models of IDD. The former display cellular and matrix changes in IVDs similar to those in degenerative human IVDs, whereas the latter maintain abundant vacuolated NC-like cells in the NP (72). FN1, Prolargin, and COMP upregulated in SM/J mice, which is consistent with observations in degenerative human 
Table II. Differentially expressed proteins enriched in the PI3K/AKT, AGE-RAGE, p53 and TGF- $\beta$ signaling pathways.

\begin{tabular}{|c|c|c|c|}
\hline Tissue & Enriched signaling pathway & Increased protein expression & Decrease protein expression \\
\hline \multirow[t]{3}{*}{$\mathrm{LF}$} & $\mathrm{PI} 3 \mathrm{~K} / \mathrm{AKT}$ & $\begin{array}{l}\text { Type VI collagen, FN1, COMP, } \\
\text { chondroadherin }\end{array}$ & COL1A1, COL1A 2 \\
\hline & AGE-RAGE & FN1 & COL1A1, COL1A2 \\
\hline & p53 & $\begin{array}{l}\text { Insulin-like growth factor-binding } \\
\text { protein }\end{array}$ & NA \\
\hline \multirow[t]{4}{*}{ AF (soluble) } & PI3K-AKT & THBS1, FN1 & $\begin{array}{l}\text { COL1A2, COL2A1, COL1A1, } \\
\alpha-2 \text { type VI collagen, } \alpha-3 \text { type VI } \\
\text { collagen }\end{array}$ \\
\hline & AGE-RAGE & FN1 & COL1A2, COL1A1 \\
\hline & p53 & THBS1 & NA \\
\hline & TGF- $\beta$ & THBS1 & NA \\
\hline \multirow[t]{3}{*}{ AF (insoluble) } & PI3K/AKT & COMP, FN1 & COL2A1 \\
\hline & AGE-RAGE & A-1 type III collagen, FN1 & NA \\
\hline & TGF- $\beta$ & $\mathrm{DCN}$ & NA \\
\hline \multirow[t]{3}{*}{ NP (soluble) } & $\mathrm{PI} 3 \mathrm{~K} / \mathrm{AKT}$ & COMP, FN1 & Chondroadherin, COL2A1 \\
\hline & AGE-RAGE & FN1 & NA \\
\hline & TGF- $\beta$ & $\mathrm{DCN}$ & NA \\
\hline \multirow[t]{2}{*}{ NP (insoluble) } & PI3K/AKT & COL1A2, FN1, COMP, COL1A1 & COL2A1 \\
\hline & AGE-RAGE & COL1A2, FN1, COL1A1 & COL2A1 \\
\hline
\end{tabular}

AGE-RAGE, advanced glycation end products-receptor for advanced glycation endproducts; AF, annulus fibrosus; THBS1, thrombospondin 1; COL1A1, $\alpha$-1 type I collagen; COL1 A2, $\alpha$-2 type I collagen; COL2A1, $\alpha-1$ type II collagen; COMP, cartilage oligomeric matrix protein; FN1, fibronectin 1; LF, ligamentum flavum; NA, not applicable; NP, nucleus pulposus; TGF- $\beta$, transforming growth factor $\beta$; DCN, decorin.

IVDs (73). In addition, the upregulation of collagen, such as $\alpha-1$ type VI and type V collagen expression, is observed in SM/J mice (73). These changes indicate ECM enrichment in SM/J mice, with processes such as chondrogenic differentiation and fibrillogenesis likely to be taking place. Notably, chondrocyte markers such as SOX9 and COL2A1 are detected at the edge of the NP region, close to the AF, which has been observed in other mouse strains (74). Thus, chondrocyte markers may serve an important role in the process of IVD degeneration in mice.

\section{Clinical proteomic analysis of body fluids from patients with degenerative spinal disorders}

The majority of lumbar disk herniation (LDH) cases are caused by IDD (75); however, the pathophysiological mechanism of disc herniation is not fully understood. Owing to the compression of the NP on the nerve root, many of the DEPs in the CSF of patients with $\mathrm{LDH}$ are associated with neurons and pain; for example, Lin et al reported that a total of nine proteins were detected at high levels in the CSF of LDH patients, including cystatin $\mathrm{C}$ and APO A-IV, whereas five proteins were found to be decreased, including creatine kinase B-type and SOD1 (Table I) (76). In addition, APOL1, which exists in endothelial cells and is closely related to atherosclerotic iliac arteries, is regulated by tumor necrosis factor- $\alpha$ (TNF- $\alpha)$, and upregulated in the serum of people suffering from $\operatorname{LDH}(77,78)$. This higher expression of APOL1 may be responsible for the degeneration, because TNF- $\alpha$ is involved in the inflammation induced by LDH (79). Similarly, APOM which was downregulated in serum of LDH patients is an immunity-associated gene adjacent to the TNF- $\alpha$ and lymphotoxin genes (80). However, the explanation behind the downregulation of APOM in the serum of LDH patients requires further study.

\section{Differentially regulated proteins and their signaling pathways in degenerative spinal disorders}

$\alpha-2$ COL1 forms one of the chains for COL1 and the structural disturbance of this protein is involved in bone development (81). There is not enough evidence to prove the link between bone development and IDD except for the downregulation of COLA2. COL2 is a major component of cartilage, and mutations in this protein have been reported to contribute to type II collagenopathies (82). The expression levels of FN1, one of the major components of the ECM that binds a large number of molecules related to signal transduction and cell adhesion, is reportedly increased in degenerating discs, which is related to the change in the organizational structure $(83,84)$. Furthermore, COMP, which is found in the ECM as an integral part of ligaments and tendons, is believed to serve a role in cellular proliferation and apoptosis, in addition to regulating cell movement and attachment (85). A previous study demonstrated that the abnormal expression of COMP and SOX9 is associated with cartilage degeneration in OA (86), and another study reported that alongside CILP and HTRA1, COMP serves as a biomarker that may be involved in the process of IDD (10).

A previous study indicated that downregulated microRNAs (including hsa-miR-125b-1-3p and hsa-miR-1184) 
and upregulated genes (including AP2 associated kinase 1 and hemoglobin subunit $\beta$ ) between normal and degenerative discs are involved in the PI3K/AKT signaling pathway (87). The activation of the PI3K/AKT pathway serves an important role in protecting cells from harmful physiological processes, such as cellular apoptosis, oxidative damage, and a hypoxic microenvironment, and has been found to protect against IDD (88). Furthermore, it was recently demonstrated that bone morphogenetic protein 2 can inhibit cellular apoptosis and suppress the synthesis of matrix proteins via the PI3K/AKT signaling pathway, which further alleviates IDD (89).

Activation of the AGE-RAGE signaling pathway in diabetic polyneuropathy, a complication of diabetes, is commonly observed, and increased AGE-RAGE signaling exacerbates degenerative disorders of peripheral neurons (90). In fact, a recent study reported no significant difference in the GAG content or histological features between discs from non-obese diabetic mice and euglycemic littermates, but noted increases in cellular apoptosis and matrix aggrecan fragmentation (91). To determine the link between diabetes and IDD, the role of the AGE-RAGE signaling pathway in IDD requires further research.

The p53 signaling pathway is an important indicator of cellular apoptosis, and decreased expression of wild-type p53-induced phosphatase 1 is closely related to p53 activation and neuronal apoptosis (92). During periods of replicative senescence, the p53/p21/retinoblastoma pathway is activated to alleviate telomere erosion and DNA damage response $(93,94)$. Furthermore, the effects of small ubiquitin-related modifier 2 on the proliferation and senescence of NP cells has been investigated through the mediation of the p53 signaling pathway in rat models of IDD (95) which indicated that SUMOS was a potential target for IDD treatment.

TGF- $\beta$ signaling is an extensive pathway involved in developmental programs of cells, including proliferation, differentiation, homeostasis, and regeneration (96). In the IVD, TGF- $\beta$ is a major regulatory cytokine that maintains cellular differentiation and homeostasis (97). Previous research has reported that the upregulation of TGF- $\beta$ causes a decrease in $\mathrm{NF}-\kappa \mathrm{B}(98)$. The inhibition of $\mathrm{NF}-\kappa \mathrm{B}$ may play an important role in IDD (99). Furthermore, TGF- $\beta$-dependent AF cell proliferation and progressive vertebral fusions due to the loss of filamin B was involved in IDD (100). Moreover, the increased expression of COL 2 and aggrecan regulated by TGF- $\beta 1$ alleviates the degeneration of IVDs (101).

\section{Conclusions}

Main components of the matrix such as prolargin, FN1, CILP, COMP, COL1 and COL2 are significantly changed in the degenerative LF, AF, and NP. COMP is involved in cartilage degeneration in OA (102), but it has not been fully studied in IDD. Moreover, The role of AGE-RAGE signaling pathway in IDD requires further research. Despite the limitations of GO and KEGG pathway analysis, proteomic analysis still provides novel targets that aid in understanding IDD pathophysiology.

\section{Acknowledgements}

Not applicable.

\section{Funding}

The present study was supported by The National Natural Science Foundation of China (grant nos. 81672215, 81572186, 81472076, 81271982 and 81401801).

\section{Availability of data and materials}

All data generated or analyzed during the present study are included in the article.

\section{Authors' contributions}

CL conceived and designed the experiment, analyzed the data and wrote the manuscript. MY and LL collected the data and analyzed the data. YaZ, QZ, CH and $\mathrm{HW}$ performed data analysis and provided interpretation. YQZ and HL provided technical support and analyzed and interpreted the data. CQL and $\mathrm{BH}$ critically revised the article and interpreted the data. $\mathrm{CF}$ and YZ were involved in designing the experiment, analyzing the data, revising the manuscript for important intellectual content and final approval of the version to be published.

\section{Ethics approval and consent to participate}

Not applicable.

\section{Patient consent for publication}

Not applicable.

\section{Competing interests}

The authors declare that they have no competing interests.

\section{References}

1. Iorio JA, Jakoi AM and Singla A: Biomechanics of degenerative spinal disorders. Asian Spine J 10: 377-384, 2016.

2. Cheung KM, Karppinen J, Chan D, Ho DW, Song YQ, Sham P, Cheah KS, Leong JC and Luk KD: Prevalence and pattern of lumbar magnetic resonance imaging changes in a population study of one thousand forty-three individuals. Spine (Phila Pa 1976) 34: 934-940, 2009.

3. Szpalski M and Gunzburg R: Lumbar spinal stenosis in the elderly: An overview. Eur Spine J 12 (Suppl 2): S170-S175, 2003.

4. Alini M, Eisenstein SM, Ito K, Little C, Kettler AA, Masuda K, Melrose J, Ralphs J, Stokes I and Wilke HJ: Are animal models useful for studying human disc disorders/degeneration? Eur Spine J 17: 2-19, 2008.

5. Adams MA and Roughley PJ: What is intervertebral disc degeneration, and what causes it? Spine (Phila Pa 1976) 31: 2151-2161, 2006.

6. Takatalo J, Karppinen J, Niinimäki J, Taimela S, Näyhä S, Mutanen P, Sequeiros RB, Kyllönen E and Tervonen O: Does lumbar disc degeneration on magnetic resonance imaging associate with low back symptom severity in young Finnish adults? Spine (Phila Pa 1976) 36: 2180-2189, 2011.

7. Risbud MV and Shapiro IM: Role of cytokines in intervertebral disc degeneration: Pain and disc content. Nat Rev Rheumatol 10: 44-56, 2014.

8. Zhang C, Chen Z, Meng X, Li M, Zhang L and Huang A: The involvement and possible mechanism of pro-inflammatory tumor necrosis factor alpha (TNF- $\alpha$ ) in thoracic ossification of the ligamentum flavum. PLoS One 12: e0178986, 2017.

9. Battié MC, Videman T, Levälahti E, Gill K and Kaprio J: Genetic and environmental effects on disc degeneration by phenotype and spinal level: A multivariate twin study. Spine (Phila Pa 1976) 33: 2801-2808, 2008. 
10. Yee A, Lam MP, Tam V, Chan WC, Chu IK, Cheah KS Cheung KM and Chan D: Fibrotic-like changes in degenerate human intervertebral discs revealed by quantitative proteomic analysis. Osteoarthritis Cartilage 24: 503-513, 2016.

11. Kamita M, Mori T, Sakai Y, Ito S, Gomi M, Miyamoto Y, Harada A, Niida S, Yamada T, Watanabe $\mathrm{K}$ and Ono $\mathrm{M}$. Proteomic analysis of ligamentum flavum from patients with lumbar spinal stenosis. Proteomics 15: 1622-1630, 2015.

12. Ai C and Kong CL: GPS: A machine learning-based approach integrating multiple gene set analysis tools for better prioritization of biologically relevant pathways. J Genet Genomics 45 : 489-504, 2018

13. Wu J, Mao X, Cai T, Luo J and Wei L: KOBAS server: A web-based platform for automated annotation and pathway identification. Nucleic Acids Res 34: W720-W724, 2006.

14. Xie C, Mao X, Huang J, Ding Y, Wu J, Dong S, Kong L, Gao G Li CY and Wei L: KOBAS 2.0: A web server for annotation and identification of enriched pathways and diseases. Nucleic Acids Res 39: W316-W322, 2011.

15. Kudo S, Ono $M$ and Russell WJ: Ossification of thoracic ligamenta flava. AJR Am J Roentgenol 141: 117-121, 1983.

16. Hur JW, Kim BJ, Park JH, Kim JH, Park YK, Kwon TH and Moon HJ: The mechanism of ligamentum flavum hypertrophy: Introducing angiogenesis as a critical link that couples mechanical stress and hypertrophy. Neurosurgery 77: 274-282, 2015.

17. Misawa H, Ohtsuka K, Nakata K and Kinoshita H: Embryological study of the spinal ligaments in human fetuses. J Spinal Disord 7: 495-498, 1994

18. Nguyen AD, Itoh S, Jeney V, Yanagisawa H, Fujimoto $M$, Ushio-Fukai $\mathrm{M}$ and Fukai T: Fibulin-5 is a novel binding protein for extracellular superoxide dismutase. Circ Res 95: 1067-1074, 2004.

19. Liu X, Zhao Y, Gao J, Pawlyk B, Starcher B, Spencer JA, Yanagisawa $\mathrm{H}, \mathrm{Zuo} \mathrm{J}$ and $\mathrm{Li} \mathrm{T}$ : Elastic fiber homeostasis requires lysyl oxidase-like 1 protein. Nat Genet 36: 178-182, 2004.

20. Postacchini F, Gumina S, Cinotti G, Perugia D and DeMartino C: Ligamenta flava in lumbar disc herniation and spinal stenosis. Light and electron microscopic morphology. Spine (Phila Pa 1976) 19: 917-922, 1976.

21. Wang B, Chen Z, Meng X, Li M, Yang X and Zhang C: iTRAQ quantitative proteomic study in patients with thoracic ossification of the ligamentum flavum. Biochem Biophys Res Commun 487: 834-839, 2017.

22. Batista MA, Nia HT, Önnerfjord P, Cox KA, Ortiz C Grodzinsky AJ, Heinegård D and Han L: Nanomechanical phenotype of chondroadherin-null murine articular cartilage. Matrix Biol 38: 84-90, 2014.

23. McEwan PA, Scott PG, Bishop PN and Bella J: Structural correlations in the family of small leucine-rich repeat proteins and proteoglycans. J Struct Biol 155: 294-305, 2006.

24. Hildebrand $\mathrm{A}$, Romarís M, Rasmussen LM, Heinegård D, Twardzik DR, Border WA and Ruoslahti E: Interaction of the small interstitial proteoglycans biglycan, decorin and fibromodulin with transforming growth factor beta. Biochem J 302 527-534, 1994

25. Zhang G, Ezura Y, Chervoneva I, Robinson PS, Beason DP, Carine ET, Soslowsky LJ, Iozzo RV and Birk DE: Decorin regulates assembly of collagen fibrils and acquisition of biomechanical properties during tendon development. J Cell Biochem 98: 1436-1449, 2006

26. Seki S, Kawaguchi Y, Chiba K, Mikami Y, Kizawa H, Oya T, Mio F, Mori M, Miyamoto Y, Masuda I, et al: A functional SNP in CILP, encoding cartilage intermediate layer protein, is associated with susceptibility to lumbar disc disease. Nat Genet 37 : 607-612, 2005

27. Sairyo K, Biyani A, Goel V, Leaman D, Booth R Jr, Thomas J, Gehling D, Vishnubhotla L, Long $R$ and Ebraheim N: Pathomechanism of ligamentum flavum hypertrophy: A multidisciplinary investigation based on clinical, biomechanical, histologic, and biologic assessments. Spine (Phila Pa 1976) 30 2649-2656, 2005.

28. Kelempisioti A, Eskola PJ, Okuloff A, Karjalainen U, Takatalo J, Daavittila I, Niinimäki J, Sequeiros RB, Tervonen O, Solovieva S, et al: Genetic susceptibility of intervertebral disc degeneration among young Finnish adults. BMC Med Genet 12: $153,2011$.

29. Zhou T, Du L, Chen C, Han C, Li X, Qin A, Zhao C, Zhang K and Zhao J: Lysophosphatidic acid induces ligamentum flavum hypertrophy through the LPAR1/Akt pathway. Cell Physiol Biochem 45: 1472-1486, 2018.
30. Hara K, Shiga A, Fukutake T, Nozaki H, Miyashita A, Yokoseki A, Kawata H, Koyama A, Arima K, Takahashi T, et al: Association of HTRA1 mutations and familial ischemic cerebral small-vessel disease. N Engl J Med 360: 1729-1739, 2009.

31. Tiaden AN and Richards PJ: The emerging roles of HTRA1 in musculoskeletal disease. Am J Pathol 182: 1482-1488, 2013.

32. Dewan A, Liu M, Hartman S, Zhang SS, Liu DT, Zhao C, Tam PO, Chan WM, Lam DS, Snyder M, et al: HTRA1 promoter polymorphism in wet age-related macular degeneration. Science 314: 989-992, 2006.

33. Tsuchiya A, Yano M, Tocharus J, Kojima H, Fukumoto M, Kawaichi M and Oka C: Expression of mouse HtrA1 serine protease in normal bone and cartilage and its upregulation in joint cartilage damaged by experimental arthritis. Bone 37 : 323-336, 2005.

34. Grau S, Richards PJ, Kerr B, Hughes C, Caterson B, Williams AS, Junker U, Jones SA, Clausen T and Ehrmann M: The role of human HtrA1 in arthritic disease. J Biol Chem 281: 6124-6129.

35. Bogduk N: Functional anatomy of the spine. Handb Clin Neurol 136: 675-688, 2016.

36. Feng C, Liu H, Yang M, Zhang Y, Huang B and Zhou Y: Disc cell senescence in intervertebral disc degeneration: Causes and molecular pathways. Cell Cycle 15: 1674-1684, 2016

37. Gruber HE, Hoelscher G, Ingram JA and Hanley EN Jr: Culture of human anulus fibrosus cells on polyamide nanofibers: Extracellular matrix production. Spine (Phila Pa 1976) 34: 4-9, 2009.

38. Antoniou J, Steffen T, Nelson F, Winterbottom N, Hollander AP, Poole RA, Aebi M and Alini M: The human lumbar intervertebral disc: Evidence for changes in the biosynthesis and denaturation of the extracellular matrix with growth, maturation, ageing, and degeneration. J Clin Invest 98: 996-1003, 1996.

39. Johnson WE, Wootton A, El Haj A, Eisenstein SM, Curtis AS and Roberts S: Topographical guidance of intervertebral disc cell growth in vitro: Towards the development of tissue repair strategies for the anulus fibrosus. Eur Spine J 15 (Suppl 3): S389-S396, 2006.

40. Singh K, Masuda K, Thonar EJ, An HS and Cs-Szabo G: Age-related changes in the extracellular matrix of nucleus pulposus and anulus fibrosus of human intervertebral disc. Spine (Phila Pa 1976) 34: 10-6, 2009.

41. Minogue BM, Richardson SM, Zeef LA, Freemont AJ and Hoyland JA: Transcriptional profiling of bovine intervertebral disc cells: Implications for identification of normal and degenerate human intervertebral disc cell phenotypes. Arthritis Res Ther 12: R22, 2010.

42. Rutges J, Creemers LB, Dhert W, Milz S, Sakai D, Mochida J, Alini $\mathrm{M}$ and Grad S: Variations in gene and protein expression in human nucleus pulposus in comparison with annulus fibrosus and cartilage cells: Potential associations with aging and degeneration. Osteoarthritis Cartilage 18: 416-423, 2010.

43. Johnson WE, Patterson AM, Eisenstein SM and Roberts S: The presence of pleiotrophin in the human intervertebral disc is associated with increased vascularization: An immunohistologic study. Spine (Phila Pa 1976) 32: 1295-1302, 2007.

44. Sarath Babu N, Krishnan S, Brahmendra Swamy CV, Venkata Subbaiah GP, Gurava Reddy AV and Idris MM: Quantitative proteomic analysis of normal and degenerated human intervertebral disc. Spine J 16: 989-1000, 2016.

45. Hofmann K and Falquet L: A ubiquitin-interacting motif conserved in components of the proteasomal and lysosomal protein degradation systems. Trends Biochem Sci 26: 347-350, 2001.

46. Feng P, Scott CW, Cho NH, Nakamura H, Chung $\mathrm{YH}$, Monteiro MJ and Jung JU: Kaposi's sarcoma-associated herpesvirus K7 protein targets a ubiquitin-like/ubiquitin-associated domain-containing protein to promote protein degradation. Mol Cell Biol 24: 3938-3948, 2004

47. Duarri A, Nibbeling E, Fokkens MR, Meijer M, Boddeke E, Lagrange E, Stevanin G, Brice A, Durr A and Verbeek DS: Erratum to: The L450F [Corrected] mutation in KCND3 brings spinocerebellar ataxia and Brugada syndrome closer together. Neurogenetics 16: 243, 2015

48. Ye D, Liang W, Dai L, Zhou L, Yao Y, Zhong X, Chen H and Xu J: Comparative and quantitative proteomic analysis of normal and degenerated human annulus fibrosus cells. Clin Exp Pharmacol Physiol 42: 530-536, 2015

49. Tsukahara F, Yoshioka T and Muraki T: Molecular and functional characterization of HSC54, a novel variant of human heat-shock cognate protein 70. Mol Pharmacol 58: 1257-1263, 2000. 
50. Persico MG, Viglietto G, Martini G, Toniolo D, Paonessa G, Moscatelli C, Dono R, Vulliamy T, Luzzatto L and D'Urso M: Isolation of human glucose-6-phosphate dehydrogenase (G6PD) cDNA clones: Primary structure of the protein and unusual 5'non-coding region. Nucleic Acids Res 14: 2511-2522, 1986.

51. Feng C, Zhang Y, Yang M, Lan M, Liu H, Huang B and Zhou Y: Oxygen-sensing Nox4 generates genotoxic ROS to induce premature senescence of nucleus pulposus cells through MAPK and NF-кB pathways. Oxid Med Cell Longev 2017: 7426458, 2017.

52. Kamboh MI, Barmada MM, Demirci FY, Minster RL, Carrasquillo MM, Pankratz VS, Younkin SG, Saykin AJ; Alzheimer's Disease Neuroimaging Initiative, Sweet RA, et al: Genome-wide association analysis of age-at-onset in Alzheimer's disease. Mol Psychiatry 17: 1340-1346, 2012.

53. Brown DA and Sihra TS: Presynaptic signaling by heterotrimeric G-proteins. Handb Exp Pharmacol: 207-60, 2008.

54. Sajjadi FG and Firestein GS: cDNA cloning and sequence analysis of the human A3 adenosine receptor. Biochim Biophys Acta 1179: 105-107, 1993

55. Salvatore CA, Jacobson MA, Taylor HE, Linden J and Johnson RG: Molecular cloning and characterization of the human A3 adenosine receptor. Proc Natl Acad Sci USA 90: 10365-10369, 1993.

56. Honsho M, Asaoku S and Fujiki Y: Posttranslational regulation of fatty acyl-CoA reductase 1, Farl, controls ether glycerophospholipid synthesis. J Biol Chem 285: 8537-8542, 2010.

57. Samland AK and Sprenger GA: Transaldolase: From biochemistry to human disease. Int J Biochem Cell Biol 41: 1482-1494, 2009.

58. Gauci S, Helbig AO, Slijper M, Krijgsveld J, Heck AJ and Mohammed S: Lys-N and trypsin cover complementary parts of the phosphoproteome in a refined SCX-based approach. Anal Chem 81: 4493-4501, 2009.

59. Dickson IR, Happey F, Pearson CH, Naylor A and Turner RL Variations in the protein components of human intervertebral disk with age. Nature 215: 52-53, 1967.

60. Sivan SS, Hayes AJ, Wachtel E, Caterson B, Merkher Y, Maroudas A, Brown S and Roberts S: Biochemical composition and turnover of the extracellular matrix of the normal and degenerate intervertebral disc. Eur Spine J 23 (Suppl 3): S344-S353, 2014

61. Elliott DM and Setton LA: Anisotropic and inhomogeneous tensile behavior of the human anulus fibrosus: Experimental measurement and material model predictions. J Biomech Eng 123: 256-263, 2001.

62. Erwin WM, DeSouza L, Funabashi M, Kawchuk G, Karim MZ, Kim S, Mädler S, Matta A, Wang X and Mehrkens KA: The biological basis of degenerative disc disease: Proteomic and biomechanical analysis of the canine intervertebral disc. Arthritis Res Ther 17: 240, 2015.

63. Markolf KL and Morris JM: The structural components of the intervertebral disc. A study of their contributions to the ability of the disc to withstand compressive forces. J Bone Joint Surg Am 56: 675-687, 1974.

64. Pettine KA, Murphy MB, Suzuki RK and Sand TT: Percutaneous injection of autologous bone marrow concentrate cells significantly reduces lumbar discogenic pain through 12 months. Stem Cells 33: 146-156, 2015.

65. Shu CC, Smith MM, Smith SM, Dart AJ, Little CB and Melrose J: A histopathological scheme for the quantitative scoring of intervertebral disc degeneration and the therapeutic utility of adult mesenchymal stem cells for intervertebral disc regeneration. Int J Mol Sci 18: pii: E1049, 2017.

66. Yang F, Leung VY, Luk KD, Chan D and Cheung KM: Mesenchymal stem cells arrest intervertebral disc degeneration through chondrocytic differentiation and stimulation of endogenous cells. Mol Ther 17: 1959-1966, 2009.

67. Meisel HJ, Agarwal N, Hsieh PC, Skelly A, Park JB, Brodke D, Wang JC, Yoon ST and Buser Z: Cell therapy for treatment of intervertebral disc degeneration: A systematic review. Global Spine J 9 (1 Suppl): 39S-52S, 2019.

68. Korecki CL, Taboas JM, Tuan RS and Iatridis JC: Notochordal cell conditioned medium stimulates mesenchymal stem cell differentiation toward a young nucleus pulposus phenotype. Stem Cell Res Ther 1: 18, 2010.

69. Steck E, Bertram H, Abel R, Chen B, Winter A and Richter W Induction of intervertebral disc-like cells from adult mesenchymal stem cells. Stem Cells 23: 403-411, 2005.

70. Sive JI, Baird P, Jeziorsk M, Watkins A, Hoyland JA and Freemont AJ: Expression of chondrocyte markers by cells of normal and degenerate intervertebral discs. Mol Pathol 55: 91-97, 2002.
71. Risbud MV, Di Martino A, Guttapalli A, Seghatoleslami R, Denaro V, Vaccaro AR, Albert TJ and Shapiro IM: Toward an optimum system for intervertebral disc organ culture: TGF-beta 3 enhances nucleus pulposus and anulus fibrosus survival and function through modulation of TGF-beta-R expression and ERK signaling. Spine (Phila Pa 1976) 31: 884-890, 2006.

72. Purmessur D, Schek RM, Abbott RD, Ballif BA, Godburn KE and Iatridis JC: Notochordal conditioned media from tissue increases proteoglycan accumulation and promotes a healthy nucleus pulposus phenotype in human mesenchymal stem cells. Arthritis Res Ther 13: R81, 2011.

73. Zhang Y, Xiong C, Kudelko M, Li Y, Wang C, Wong YL, Tam V, Rai MF, Cheverud J, Lawson HA, et al: Early onset disc degeneration in $\mathrm{SM} / \mathrm{J}$ mice is associated with ion transport systems and fibrotic changes. Matrix Biol 70: 123-139, 2018.

74. Tam V, Chan WCW, Leung VYL, Cheah KSE, Cheung KMC, Sakai D, McCann MR, Bedore J, Séguin CA and Chan D: Histological and reference system for the analysis of mouse intervertebral disc. J Orthop Res 36: 233-243, 2018.

75. Donnally IC, Hanna A and Varacallo M: Lumbar degenerative disk disease, in StatPearls. StatPearls Publishing. StatPearls Publishing LLC.: Treasure Island (FL), 2019.

76. Liu XD, Zeng BF, Xu JG, Zhu HB and Xia QC: Proteomic analysis of the cerebrospinal fluid of patients with lumbar disk herniation. Proteomics 6: 1019-1028, 2006.

77. Xie P, Liu B, Chen R, Yang B, Dong J and Rong L: Comparative analysis of serum proteomes: Identification of proteins associated with sciatica due to lumbar intervertebral disc herniation. Biomed Rep 2: 693-698, 2014.

78. Horrevoets AJ, Fontijn RD, van Zonneveld AJ, de Vries CJ, ten Cate JW and Pannekoek H: Vascular endothelial genes that are responsive to tumor necrosis factor-alpha in vitro are expressed in atherosclerotic lesions, including inhibitor of apoptosis protein-1, stannin, and two novel genes. Blood 93: 3418-3431, 1999.

79. Murata Y,Nannmark U,Rydevik B, Takahashi K and Olmarker K: The role of tumor necrosis factor-alpha in apoptosis of dorsal root ganglion cells induced by herniated nucleus pulposus in rats. Spine (Phila Pa 1976) 33: 155-162, 2008.

80. Luo G, Zhang X, Nilsson-Ehle P and Xu N: Apolipoprotein M. Lipids Health Dis 3: 21, 2004.

81. Palomo T, Vilaca T and Lazaretti-Castro M: Osteogenesis imperfecta: Diagnosis and treatment. Curr Opin Endocrinol Diabetes Obes 24: 381-388, 2017.

82. Deng H, Huang X and Yuan L: Molecular genetics of the COL2A1-related disorders. Mutat Res Rev Mutat Res 768: 1-13, 2016.

83. Zollinger AJ and Smith ML: Fibronectin, the extracellular glue. Matrix Biol 60-61: 27-37, 2017.

84. Oegema TR Jr Johnson SL, Aguiar DJ and Ogilvie JW: Fibronectin and its fragments increase with degeneration in the human intervertebral disc. Spine (Phila Pa 1976) 25: 2742-2747, 2000.

85. Kook SH, Lim SS, Cho ES, Lee YH, Han SK, Lee KY, Kwon J, Hwang JW, Bae CH, Seo YK and Lee JC: COMP-angiopoietin 1 increases proliferation, differentiation, and migration of stem-like cells through Tie-2-mediated activation of p38 MAPK and PI3K/Akt signal transduction pathways. Biochem Biophys Res Commun 455: 371-377, 2014

86. Zhang Q, Ji Q, Wang X, Kang L, Fu Y, Yin Y, Li Z, Liu Y, $\mathrm{Xu} X$ and Wang Y: SOX9 is a regulator of ADAMTSs-induced cartilage degeneration at the early stage of human osteoarthritis. Osteoarthritis Cartilage 23: 2259-2268, 2015

87. Mo S, Liu C, Chen L, Ma Y, Liang T, Xue J, Zeng H and Zhan X: KEGG-expressed genes and pathways in intervertebral disc degeneration: Protocol for a systematic review and data mining. Medicine (Baltimore) 98: e15796, 2019.

88. Ouyang ZH, Wang WJ, Yan YG, Wang B and Lv GH: The PI3K/Akt pathway: A critical player in intervertebral disc degeneration. Oncotarget 8: 57870-57881, 2017.

89. Tan Y, Yao X, Dai Z, Wang Y and Lv G: Bone morphogenetic protein 2 alleviated intervertebral disc degeneration through mediating the degradation of ECM and apoptosis of nucleus pulposus cells via the PI3K/Akt pathway. Int J Mol Med 43: 583-592, 2019.

90. Zochodne DW: Mechanisms of diabetic neuron damage: Molecular pathways. Handb Clin Neurol 126: 379-399, 2014.

91. Russo F, Ambrosio L, Ngo K, Vadalà G, Denaro V, Fan Y, Sowa G, Kang JD and Vo N: The role of type I diabetes in intervertebral disc degeneration. Spine (Phila Pa 1976) 44: 1177-1185, 2019. 
92. Ma X, Han J, Wu Q, Liu H, Shi S, Wang C, Wang Y, Xiao J, Zhao J, Jiang $J$ and Wan C: Involvement of dysregulated Wip1 in manganese-induced p53 signaling and neuronal apoptosis. Toxicol Lett 235: 17-27, 2015.

93. Ben-Porath I and Weinberg RA: The signals and pathways activating cellular senescence. Int J Biochem Cell Biol 37: 961-976, 2005.

94. Muller M: Cellular senescence: Molecular mechanisms, in vivo significance, and redox considerations. Antioxid Redox Signal 11: 59-98, 2009.

95. Jin LZ, Lu JS and Gao JW: Silencing SUMO2 promotes protection against degradation and apoptosis of nucleus pulposus cells through p53 signaling pathway in intervertebral disc degeneration. Biosci Rep 38: pii: BSR20171523, 2018.

96. Massagué J: TGF $\beta$ signalling in context. Nat Rev Mol Cell Biol 13: 616-630, 2012

97. Chen G, Deng C and Li YP: TGF- $\beta$ and BMP signaling in osteoblast differentiation and bone formation. Int J Biol Sci 8: 272-288, 2012.

98. Cao C, Zou J, Liu X, Shapiro A, Moral M, Luo Z, Shi Q, Liu J, Yang $\mathrm{H}$ and Ebraheim N: Bone marrow mesenchymal stem cells slow intervertebral disc degeneration through the $\mathrm{NF}-\kappa \mathrm{B}$ pathway. Spine J 15: 530-538, 2015.
99. Lu L, Hu J, Wu Q, An Y, Cui W, Wang J and Ye Z: Berberine prevents human nucleus pulposus cells from ILlbetainduced extracellular matrix degradation and apoptosis by inhibiting the NFkappaB pathway. Int J Mol Med 43: 1679-1686, 2019.

100.Zieba J, Forlenza KN, Khatra JS, Sarukhanov A, Duran I, Rigueur D, Lyons KM, Cohn DH, Merrill AE and Krakow D: TGF $\beta$ and BMP dependent cell fate changes due to loss of filamin $\mathrm{b}$ produces disc degeneration and progressive vertebral fusions. PLoS Genet 12: e1005936, 2016.

101. Yang H, Cao C, Wu C, Yuan C, Gu Q, Shi Q and Zou J: TGF- $\beta 1$ suppresses inflammation in cell therapy for intervertebral disc degeneration. Sci Rep 5: 13254, 2015.

102. Posey KL, Coustry F and Hecht JT: Cartilage oligomeric matrix protein: COMPopathies and beyond. Matrix Biol 71-72: 161-173, 2018.

(i) This work is licensed under a Creative Commons Attribution-NonCommercial-NoDerivatives 4.0 International (CC BY-NC-ND 4.0) License. 